\title{
Response of Viral Specific CD4 T Cells to in vitro Stimulation with Vaccine and Wild Measles Virus Strains in Vaccinated and Naturally Infected Subjects
}

\author{
AGNIESZKA CZĘŚCIK, MILENA DUNAL-SZCZEPANIAK, AGNIESZKA TRZCIŃSKA \\ and JOANNA SIENNICKA* \\ Department of Virology, National Institute of Public Health - National Institute of Hygiene, \\ Warsaw, Poland
}

Submitted 4 February 2014, accepted 12 May 2013

\begin{abstract}
With the implementation of the WHO strategic plan for the elimination of measles, the number of measles cases in European Region has decreased. However, outbreaks are still observed. Although most measles cases affect unvaccinated individuals, cases with vaccinated persons are also reported. Furthermore, it was described that a high percentage of young people in Poland exhibit no presence of anti-MeV IgG despite the high level of vaccination covering no less than $97 \%$ of the Polish population. Strong evidence exists that immunity to measles is complex and depends on both the humoral and cellular response and although antibodies have been used as correlates of immunity, it is increasingly being considered that antibody-based definitions of vaccine success or failure may be incomplete. Here, we investigated immunity to measles as the reactivity of CD4 T cells to stimulation with vaccine as well as wild strains of measles virus $(\mathrm{MeV})$ isolated in Poland, in young vaccinated persons and subjects infected naturally. Evidence for the presence of MeV-specific memory cells years after infection or vaccination was found, however the cells of vaccinees and naturally infected subjects reacted differently in contact with wild and vaccine $\mathrm{MeV}$ strains. Furthermore, the presence of a significant proportion of non-responder vaccinees was observed. In conclusion, our results may have implications for studies on the monitoring of the complexity of post-vaccine immune response.
\end{abstract}

Key words: MeV, vaccination, natural infection, CD69, IFN

\section{Introduction}

Measles is a vaccine-preventable disease that could be eliminated by vaccination strategies. With the implementation of the World Health Organization (WHO) strategic plan for the measles elimination, the number of measles cases in European Region has decreased. However, outbreaks are still observed. Although most measles cases affect unvaccinated individuals, cases with vaccinated persons are also reported. In 2006 in Poland 44 out of 120 registered measles cases concerned vaccinated individuals: 26 persons vaccinated with one dose of anti-measles vaccine and 18 with two doses (Czarkowski et al., 2006). Furthermore it was described that high percentage of young people in Poland exhibit no presence of anti-MeV IgG (Częścik et al., 2012; Sadowska-Galera, 2009) despite the high level of vaccination covering no less than $97 \%$ of the Polish population (Czarkowski et al., 2010). However, it should be pointed that the incidence of measles in Poland in the last years was not high. Over 2006-2012 period the highest rate was observed in 2006 and it was 0.31 per 100 thousand.

Although the antibody levels correlate well with immunity, it is known that the cellular response plays an especially important role in controlling viral infections. Thus, the lack of antibodies does not necessarily indicate susceptibility to measles, but also on the contrary, the presence of antibodies does not rule out the possibility of infection (Chen et al., 1990).

The above mentioned situation in Poland (high percentage of seronegative individuals) raises questions about the immunity of vaccinated subjects: whether, despite the absence of antibodies, immunological memory was created? If yes, is the response to wild viruses isolated in Poland is as strong as to the vaccine virus?

In this paper we describe the effect of stimulation with $\mathrm{MeV}$ on the expression of activation markers on CD4 T cells in three groups of individuals with different level of humoral immunity and different history of measles immunity acquisition.

* Corresponding author: J. Siennicka, Department of Virology, National Institute of Public Health - National Institute of Hygiene, Chocimska no 24, 00-791 Warsaw, Poland; phone: +48 22 5421234; e-mail address: jsiennicka@pzh.gov.pl 


\section{Experimental}

\section{Materials and Methods}

Study group. The study was conducted using specimens obtained from 55 volunteers. Volunteers were selected on the base of age, anti-MeV IgG presence, documented vaccination against measles (annotation in personal immunization sheet and/or record in child's health booklet). Three groups were created (Table I): unvaccinated against measles, but seropositive as a result of natural infection subjects born before 1972 (group 1), vaccinated against measles with negative or equivocal result of anti-MeV IgG test born after 1974 (group 2), vaccinated against measles with positive result of anti-MeV IgG test subjects born after 1974 (group 3). 1974 was taken as caesura because in this year vaccination against measles was introduced in Poland, so persons who were born in 1974 or before were unvaccinated and acquired immunity by natural measles infection (Janaszek et al., 2000).

To exclude immunological parameters which could affect immune response, leukocytes numbers (WBC), lymphocytes profile (Simultest ${ }^{\mathrm{TM}}$ IMK-Lymphocyte, Becton Dickinson) and serum cytokines level (BD ${ }^{\mathrm{TM}}$ Cytometric Bead Array, Human Th1/Th2 cytokine Kit II) were determined. The results of all subjects enrolled in the study were within the reference ranges.

Serological study. Serum samples were assayed for anti-measles specific IgG using enzyme-linked immunosorbent assay kit Enzygnost Anti-Measles Virus/IgG (Simens, formerly DadeBehring, Germany).

The tests were performed according to the manufacturer's procedure, allowing quantification by measuring the optical density (OD) of a single serum dilution in antigen and control wells. The difference of these ODs $(\Delta \mathrm{OD})$ multiplied by a correction factor were used to evaluate the qualitative result according to the following cut-off values: results with $\triangle \mathrm{OD}<0.100$ were considered as negative, results with $\triangle O D$ in range $0.100-0.200$ as equivocal and results with, $\Delta \mathrm{OD}>0.200$ as positive.
Quantitative values of anti- $\mathrm{MeV}$ IgG were calculated using the formula: $\log _{10} \mathrm{mIU} / \mathrm{ml}=\alpha^{\star} \Delta \mathrm{OD}^{\beta}$ (where $\alpha$ and $\beta$ are lot-dependent constants, as well as nominal value used to calculate the correction factor). The quantitative results were expressed in $\mathrm{mIU} / \mathrm{ml}$.

The test was standardized to the $3^{\text {rd }}$ International Standard for Anti-Measles (WHO International Standard. $3^{\text {rd }}$ International Standard for Anti-Measles. NIBSC code: 97/648. National Institute for Biological Standard and Control. Blanche Lane South Mimms Potters Bar Hertfordshire EN6 3QG UK.) containing $3000 \mathrm{mIU} / \mathrm{ml}$ anti-measles activity measured by PRNT (Plaque Reduction Neutralization Test). In four independent experiments, five double dilutions of standard serum were examinated in triplicate. It was shown (in linear model of analysis of regression) that $200 \mathrm{mIU} / \mathrm{ml}$ antimeasles activity measured by PRNT (level protection against symptomatic disease (WHO, 1993) is equivalent to $636 \mathrm{mIU} / \mathrm{ml}$ measured by ELISA test used in this study (data not shown).

Measles virus (MeV). The study was conducted with vaccine strain (E) of measles virus (Edmonston ATCC, VR-24) and two wild strains isolated in Poland: 2281/3/2006 (W1) and 2521/3/2007 (W2), belonging to two genotypes, D4 and D6 accordingly. The viruses were propagated and titrated $\left(\mathrm{TCID}_{50}\right)$ in VeroSLAM (received from Robert Koch Institute, Berlin, Germany) maintained in DMEM (Sigma, D7777) and supplemented with 10\% fetal bovine serum (Sigma, F6178), then aliquoted and stored at $-70^{\circ} \mathrm{C}$.

Stimulation. Sodium heparin whole blood samples were stimulated with $\mathrm{MeV}$ (E, W1, W2). Samples stimulated with SEB (enterotoxin B Staphylococcus aureus, S4881 Sigma) served as positive control. Non stimulated samples (NS) served as negative control.

Each blood sample was aliquoted into five parts. Four of these five aliquots were stimulated with either 400 infectious particles of each $\mathrm{MeV}$ strain or $1 \mu \mathrm{g} / \mathrm{ml}$ of SEB. $200 \mu \mathrm{l}$ of each stimulator were added to $0.5 \mathrm{ml}$ of the whole blood sample. The fifth part of each sample remained non-stimulated. The dose of $\mathrm{MeV}$ was as

Table I

Study group. Demographic data, serological characteristic and history of vaccination against measles

\begin{tabular}{|c|c|c|c|c|c|c|c|c|c|}
\hline \multirow{2}{*}{ Group } & \multirow{2}{*}{$\mathrm{n}$} & \multirow{2}{*}{$\begin{array}{l}\text { Anti-MeV } \\
\quad \text { IgG } \\
\text { presence }^{\text {a) }}\end{array}$} & \multirow{2}{*}{$\begin{array}{l}\text { Gender } \\
(\mathrm{f} / \mathrm{m})^{\mathrm{b})}\end{array}$} & \multicolumn{2}{|c|}{ Age (years) } & \multirow{2}{*}{$\begin{array}{c}\text { Anti-MeV IgG } \\
\mathrm{GMC}^{\mathrm{c})} \text { in } \mathrm{mIU} / \mathrm{ml} \\
(95 \% \mathrm{CI})^{\mathrm{d})}\end{array}$} & \multicolumn{2}{|c|}{$\begin{array}{l}\text { Vaccine administration } \\
\text { (no of vaccinees) }\end{array}$} & \multirow{2}{*}{$\begin{array}{l}\text { Time after administra- } \\
\text { tion of last dose of } \\
\text { vaccine mean interval } \\
\text { (range) in years }\end{array}$} \\
\hline & & & & Range & Average \pm SD & & one dose & two doses & \\
\hline 1 & 20 & POS & $19 / 1$ & $40-62$ & $52.6 \pm 6.3$ & $3512(2404-5140)$ & - & - & - \\
\hline 2 & 18 & NEG or EQU & $11 / 7$ & $21-36$ & $27.3 \pm 4.4$ & $153(105-221)$ & 7 & 11 & $21.1(11-35)$ \\
\hline $2 \mathrm{a}$ & 7 & NEG & $4 / 3$ & $21-35$ & $26.4 \pm 4.3$ & $71(41-120)$ & 3 & 4 & $21.6(16-33)$ \\
\hline $2 b$ & 11 & EQU & $7 / 4$ & $22-36$ & $27.9 \pm 4.6$ & $250(217-288)$ & 4 & 7 & $20.7(11-35)$ \\
\hline 3 & 17 & POS & $14 / 3$ & $18-36$ & $27.3 \pm 5.3$ & $855(578-1265)$ & 9 & 8 & $20.9(5-34)$ \\
\hline
\end{tabular}

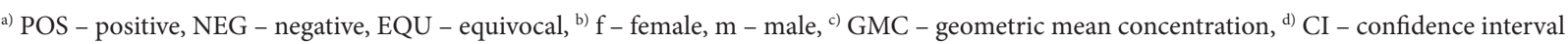



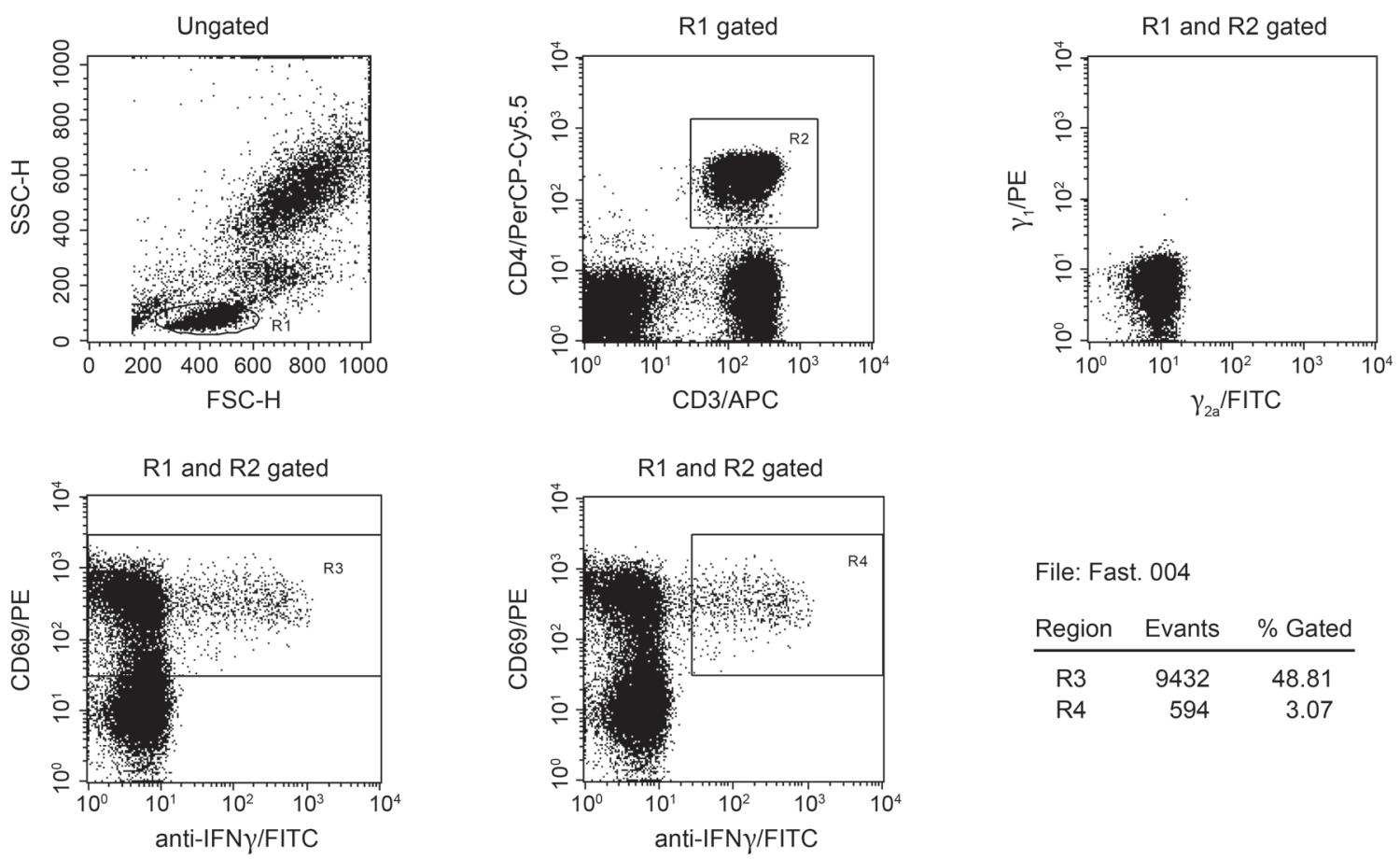

File: Fast. 004
\begin{tabular}{ccc} 
Region & Evants & $\%$ Gated \\
\hline R3 & 9432 & 48.81 \\
R4 & 594 & 3.07
\end{tabular}

Fig. 1. Gating strategy. R3 region contain CD4 T cells expressing CD69 and R4 region contain activated CD4 T cells expressing CD69 and IFN producing (CD4/CD69/IFN positive). For analysis $20000 \mathrm{CD} 4 \mathrm{~T}$ cells gated in R2 were collected. The specific response of cells to stimulus is obtained by subtracting the \% positive events in unstimulated sample (NS) from the \% positive events in the activated sample (E, W1, W2 or SEB).

high as allowed by the titer of the weakest virus strain (W1). Additionally, to all samples CD28/CD49d monoclonal antibodies were added and samples were incubated $2 \mathrm{~h}$ at $37^{\circ} \mathrm{C}$. After incubation with $\mathrm{MeV}, \mathrm{SEB}$ and costimulatory antibodies, Brefeldin A had been added to inhibit the secretion of newly synthetized cytokine and CD69. The samples were then incubated for an additional $4 \mathrm{~h}$ at $37^{\circ} \mathrm{C}$. Finally EDTA and lysing solution were added to remove adherent cells and lyse red blood cells, respectively. Prior to staining, the samples were stored at $-70^{\circ} \mathrm{C}$.

CD69 and IFN determination. After 6 hours stimulation, BD FastImmune CD4 Intracellular Cytokine Detection Kit (337185 Becton Dickinson) was used for determination of CD69 and IFN expression. After the permeabilization step, the cells were labeled with an antibody cocktail consisting of INF $\gamma /$ FITC, CD69/PE, CD4/PerCP-Cy5.5, CD3/APC. Additional samples were stained with isotypic control ( $\gamma 2 \mathrm{a} / \mathrm{FITC}$ and $\gamma 1 / \mathrm{PE})$. Stained cells were fixed and four-color analysis was performed in flow cytometer (FACSCalibur) with CellQuest software. For analysis 20000 CD4 T cells were collected. Gating strategy was shown in Fig. 1. The specific response of cells to stimulus was obtained by subtracting the $\%$ of positive events in unstimulated sample (NS) from the $\%$ of positive events in the activated sample (E, $\mathrm{W} 1, \mathrm{~W} 2$ or SEB).

Mock infected control. The stimulatory effect of VeroSLAM cell lysate was determined. Uninfected cells were prepared in the same manner as the cells used for virus propagation. Blood samples were stimulated with uninfected cell lysate (mock), cell lysate contain 400 infectious particles of $\mathrm{MeV}$ (Edmonston). Nonstimulated samples (NS) served as a negative control. The samples were processed as described above. The experiment was done in triplicate.

Statistical analysis. The parametric tests: Anova for determination of differences between groups or Student's $t$-test for two samples comparison were used for data exhibiting normal distribution. For non-normal distributed data the Kruskal-Wallis and Mann-Whitney (Wilcoxon) tests were used, respectively. Correlation between numerical variables was examined by linear regression. To compare the distribution of responders and non-responders, Fisher's exact test was used. The $\mathrm{p}<0.05$ was considered as significant. Statistical analysis was performed using Statgraphics Plus v.4.1. software.

\section{Results}

Age, anti-MeV IgG level and vaccine doses. The results of T CD4 response after in vitro stimulation with $\mathrm{MeV}$ were analysed in three groups differing in age, anti-MeV IgG presence and mode of $\mathrm{MeV}$-specific IgG acquisition (vaccination, natural infection).

While subjects naturally infected (group 1) were significantly older than vaccinees (group 2 and 3 ), the age 

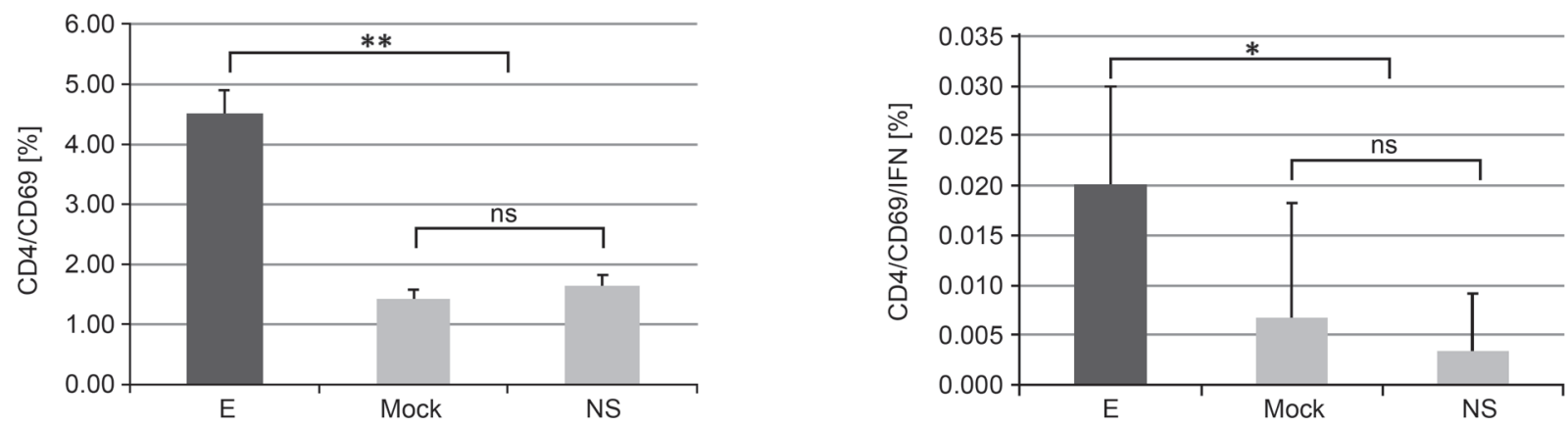

Fig. 2. Mock infected control. The frequency of CD4 T activated cells (CD4/CD69 positive - left and CD4/CD69/IFN positive - right) are shown as means \pm SD (upper bounds labelled). Blood samples were stimulated with measles virus (E), with mock infected cells (Mock) and non-stimulated control (NS). The results of three experiments were analyzed. The statistical significance of observed differences was estimated using Mann-Whitney (Wilcoxon) test. ${ }^{* *} \mathrm{p}<0.05 ;{ }^{*} \mathrm{p}<0.1 ; \mathrm{ns} \mathrm{p}>0.05$.

difference between groups 2 and 3 was not statistically significant $(\mathrm{p}=0.98)$.

The GMC of anti-MeV IgG value measured in individuals naturally infected $(3512 \mathrm{mIU} / \mathrm{ml})$ was significantly higher $(\mathrm{p}<0.001)$ compared to the value obtained by the vaccination in group $3(855 \mathrm{mIU} / \mathrm{ml})$.

Vaccinees were immunized with single or two doses of vaccine. The mean level of anti-MeV IgG in vaccinated once was higher ( $409 \mathrm{mIU} / \mathrm{ml}$ [CI95\% 206-811]) in comparison to the mean level observed in vaccinated twice $(311 \mathrm{mIU} / \mathrm{ml}$ [CI95\% 190-510]). However, this difference was not statistically significant $(\mathrm{p}=0.49)$.

Analysis of relationship between the mean interval between date of last dose of vaccine (20.97 years [CI95\% 18.34-23.60]) and anti-MeV IgG level $(352 \mathrm{mIU} / \mathrm{ml}$ [CI95\% 238-521]) measured in vaccinees from groups 2 and 3 showed no relationship between those variables $(\mathrm{p}=0.83)$.

Mock infected control. The results of control experiments showed no influence of cell lysate on stimulatory effect of measles virus (Fig. 2). The frequency of
CD4/CD69 cells in the mock control was significantly lower $(p=0.028)$ than that observed after stimulation with cell lysate containing virus. No significant differences $(p=0.19)$ were observed between non-stimulated (NS control) and mock-stimulated cells. A similar relationship was observed for the CD4/CD69/IFN frequency. However differences between $\mathrm{E}$ and mockstimulated cells reached only marginally statistical significance $(p=0.07)$.

Non-specific activation of CD4 T cells (NS and SEB controls). Percentage of CD4 cells expressing CD69 (CD4/CD69) and CD4 expressing CD69 and IFN producing (CD4/CD69/IFN) in control samples - nonstimulated (NS) and stimulated with SEB were determined (Fig. 3). All subjects responded to SEB. After SEB stimulation the mean frequency of CD4/CD69 was 32.33 (CI95\% 28.53-36.16) and 3.56 (CI95\% 2.73-4.38) of CD4/CD69/IFN. The mean frequency of activated CD4 cells in NS control was low: 3.31 (CI95\% 2.364.25) of CD4/CD69 and 0.078 (CI95\% 0.054-0.102) of CD4/CD69/IFN. Eight outliers in the NS control,

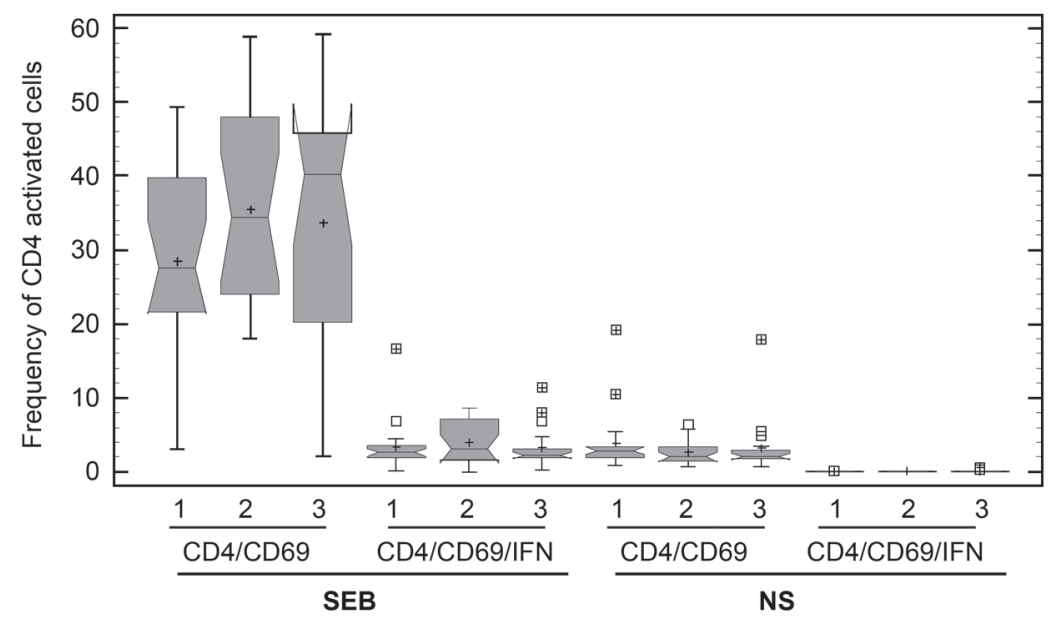

Fig. 3. Non-specific activation of CD4 T cells (NS and SEB controls). Box and whisker plot showing the distribution of CD4 T cells expressing CD69 (CD4/CD69) and CD4 expressing CD69 and IFN producing (CD4/CD69/IFN) in control samples of individuals from group 1, 2 and 3: non-stimulated NS control and SEB control - cells stimulated with S. aureus enterotoxin B. Five outliers visible in the SEB CD4/CD69/IFN control were excluded from further analysis. 


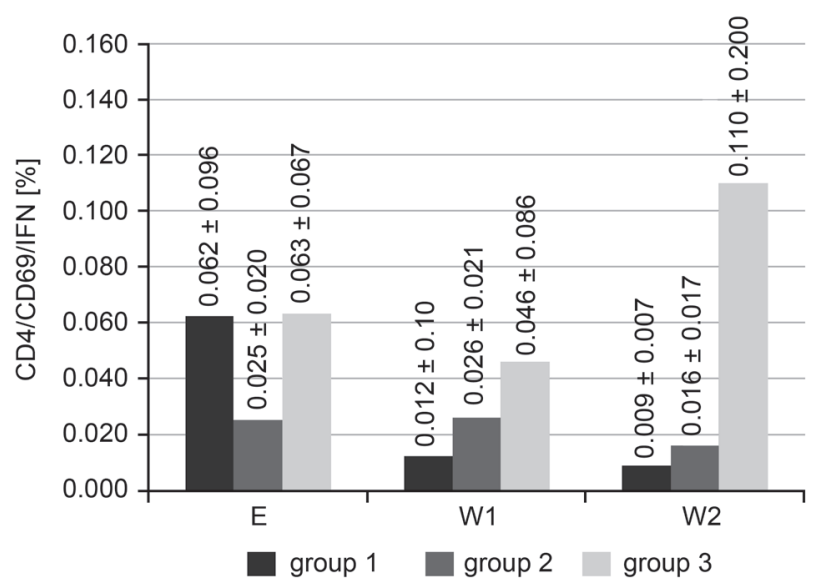

Fig. 4. MeV-specific activation of CD4 T cells. The frequency of CD4/CD69/IFN positive cells are shown as means \pm SD in blood samples collected from individuals with different history of measles (groups 1,2 and 3) after stimulation with vaccine (E) and wild strains (W1 and $\mathrm{W} 2)$ of measles virus $(\mathrm{MeV})$

four outliers in the SEB control and one outlier in both assays were identified (Fig. 3). However, statistical analysis of NS control as well as SEB control showed no differences between the three groups of investigated individuals $(p>0.05)$, the subjects exhibiting hyperactivity for stimulation (five outliers in SEB control) were excluded from further analysis. The outliers identified in NS control were not excluded, because influence of spontaneous reactivity was discriminated by subtraction of NS values from values obtained by virus-specific stimulation. As a result, for further analysis, a group of 50 subjects was created.

MeV-specific activation of T CD4 cells (E, W1, W2). The frequency of CD4 activated T cells (CD4/ CD69/IFN positive) in blood samples collected from individuals with different mode of anti-measles immunity acquisition was evaluated (Fig. 4).

The percentage of CD4 cells activated by $\mathrm{MeV}$ was much lower than that observed after SEB stimulation. In all study groups, after $\mathrm{MeV}$ stimulation no more than ten activated T cells were found: 9.8 cells after $\mathrm{E}$ stimulation (0.049\%); 5.4 cells after W1 stimulation (0.027\%) and 8.0 cells after W2 stimulation (0.040\%). SEB stimulation led to the average number of $712 \mathrm{CD} 4 / \mathrm{CD} 69 / \mathrm{IFN}$ positive cells (3.56\%).

It was observed that whereas the response of subjects in the infected naturally (group 1) and seropositive-vaccinated (group 3) after stimulation with vaccine strain was equal, the response after stimulation with wild strains was higher in the young, vaccinated groups. The CD4 $\mathrm{T}$ cell activation was similarly low irrespective of strain used for stimulation among group 2 subjects (Fig. 4). Observed differences between groups regarding the frequency of activated CD4 T cells were not statistically significant $(\mathrm{p}>0.05)$, maybe due to extremely low frequencies of investigated cells.

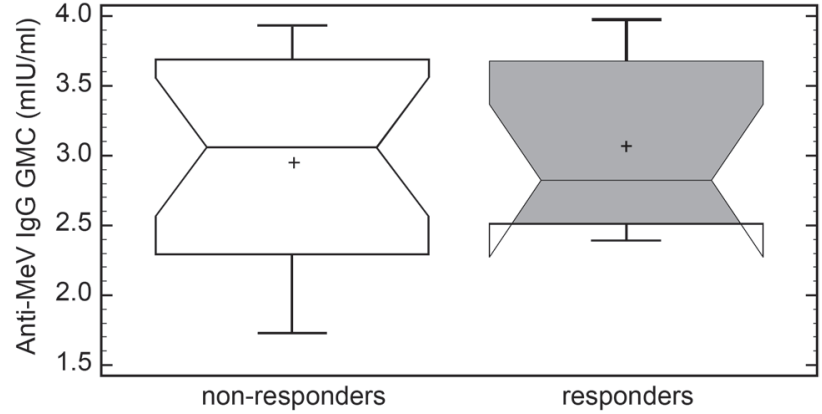

Fig. 5. Humoral versus cellular response. Box and whisker plot showing distribution of anti-MeV IgG in sera of non-responders (individuals with no evidence of CD4/CD69/IFN positive cells after stimulation with all three $\mathrm{MeV}$ strains) and responders (individuals with evidence of activated CD4 $\mathrm{T}$ cells after stimulation with all three $\mathrm{MeV}$ strains). There is no statistically significant differences between groups (Anova, $\mathrm{p}>0.05$ ).

In all three groups non-responders, defined as individuals with no evidence of CD4/CD69/IFN positive cells after stimulation with all three $\mathrm{MeV}$ strains, as well as responders - defined as individuals with positive response to all three $\mathrm{MeV}$ strains were detected. While the percentage of responders was equal in all three groups differing with level of anti-MeV IgG $(22.2 \%, 22.2 \%$ and $21.4 \%$ respectively), the percentage of individuals that had no evidence of the $\mathrm{MeV}$-specific CD4/CD69/IFN positive cells (non-responders) was the lowest in the group of the young, seropositive vaccinated individuals from group $3(28.6 \%)$ in comparison to group 1 and 2 (44.4\% and $38.9 \%$, respectively).

Humoral versus cellular response. The relationship between anti-MeV IgG level in responders and nonresponders as defined above was evaluated (Fig. 5). The $\mathrm{GMC}$ of anti-MeV IgG value measured in responders $(2659 \mathrm{mIU} / \mathrm{ml})$ was non-significantly higher $(\mathrm{p}=0.66)$ compared to the value obtained in non-responders (2 $470 \mathrm{mIU} / \mathrm{ml})$. A similar analysis was made for each $\mathrm{MeV}$ strain used for stimulation. Within study group there were 21 individuals in the blood of which we could find activated $\mathrm{CD} 4 \mathrm{~T}$ cells after stimulation with vaccine strain (E), and respectively 22 and 18 individuals after stimulation with $\mathrm{W} 1$ and W2. There were also no statistically significant differences of anti-MeV IgG level in the sera of responders and non-responders in regard to particular strain used as a stimulator $(p>0.05)$.

\section{Discussion}

Strong evidence exists that immunity to measles is complex and depends on both humoral and cellular response. Although Abs have been used as correlates of immunity, it is increasingly being considered that antibody-based definitions of vaccine success or failure may be incomplete. Cell-mediated immunity to measles 
virus has been intensively studied (Nanan et al., 2000; Ovsyannikova et al., 2003; Naniche et al., 2004; Howe et al., 2005; Haralambieva et al., 2010; Haralambieva et al., 2011; Jacobson etal., 2012). Using new techniques it was possible to measure low frequencies of lymphocytes subpopulation and thus quantifying $\mathrm{MeV}$ specific memory cells (Czerkinsky et al., 1983; Altman et al., 1996; Waldrop et al., 1997; Nanan et al., 2000). In the present study we investigated immunity to measles as reactivity of CD4 T cells to stimulation with vaccine as well as wild strains, in vaccinees and subjects infected naturally.

We observed that the anti-MeV IgG levels after natural infection were significantly higher compared to the values obtained by vaccination. This finding is consistent with generally accepted data that the attenuated vaccine induces response qualitatively similar to that obtained as a result of natural infection but with lower antibody levels (WHO, 1993). The results of studies based on large cohorts have shown that vaccineinduced anti-MeV antibodies decline with time in the absence of circulating virus (Christenson and Böttiger, 1994; Mossong et al., 1999). In a large study undertaken in a measles post-elimination environment (Haralambieva et al., 2011) it was demonstrated that 7.4 years after vaccination only $23.2 \%$ of young, vaccinated subjects had anti-MeV IgG above $1841 \mathrm{mIU} / \mathrm{ml}$ (corresponding to titer of 1052 measured by plaque reduction test), the level "suggesting total protection against viral infection/viral replication". Interestingly, taking into account this criterion, in our study only $70 \%$ of naturally infected individuals exhibited total protection, and the remaining $30 \%$ were those with risk of asymptomatic infection (anti-MeV IgG below $1841 \mathrm{mIU} / \mathrm{ml}$ ). It could suggest that antibodies contracted by natural infection also tend to wane, but after longer time, as after natural infection the antibodies titers are usually higher. The decline of anti-MeV IgG observed amongst those with a history of wild type measles infection suggests that these individuals have not experienced periodic boosting from exposure to circulating wild type viruses and this lack of transmission may indicate that Poland is entering the measles elimination phase.

In the present study we measured response after $\mathrm{MeV}$ stimulation as frequencies of CD4/CD69/IFN positive cells by FastImmune BD test. Like others (Nanan et al., 2000; Ovsyannikova et al., 2003; Dhiman et al., 2005; Haralambieva et al., 2011; Jacobson et al., 2012), we could detect MeV-specific memory cells long time after vaccination or infection. Using for stimulation highly attenuated vaccine as well as wild viruses, we observed differences in CD4/CD69/IFN frequencies in vaccinees and subjects infected naturally. It is interesting that the response of subjects infected naturally and seropositive vaccinees after Edmonston stimula- tion was equal, but was higher for vaccinees after wild strains stimulation. The differences in response after stimulation with Edmonston in comparison to the wild virus, measured as higher levels of broad cytokine panel and higher frequencies of cytokine-producing cells after stimulation has been described elsewhere (Haralambieva et al., 2010). That is indicated by our results too, however only in subjects infected naturally.

Within all three groups we observed the existence of subjects that had no evidence of CD4/CD69/IFN positive cells after $\mathrm{MeV}$ stimulation. While CD4 memory cells, like specific antibodies without booster, gradually disappear (Homann etal., 2001; Naniche et al., 2004) the highest number of such non-responders was observed among persons infected average $40-50$ years ago. Non-responders were $10 \%$ more frequent within seronegative in comparison to seropositive vaccines. This is consistent with accepted data that CD4 T cells play a crucial role for antibodies production and their long time maintenance (Halwani et al., 2006).

The major strength of our study is a precisely defined group in regards to immune parameters. Our intention was to eliminate from the study those who exhibited any deficiency that might affect the examined parameters. In particular, special attention was paid to imbalance in Th1/Th2 system. The study limitations can be identified as a small group size and in the dose of measles virus used for stimulation. Because in our study whole blood samples were used, not PBMC, the precise determination of multiplicity of infection was not possible. On the other hand, the advantage of FastImmune in comparison to PBMC testing is the small volume of blood needed for the tests. This allows for performing a larger number of determinations for a single person. Another limitation can be identified as a loss of sensitivity in determination of CD4 activated by virus-specific stimulation due to applying very restrictive criteria for discrimination of non-specific reaction (subtraction of NS value). If so, the loss of sensitivity concerned all subjects and had no effect on the comparison between groups.

Conclusions. In conclusion, as both humoral and cellular immune responses play a critical role in measles protection to define vaccine success or failure both responses should be considered together. We found evidence for the presence of $\mathrm{MeV}$-specific memory cells years after infection or vaccination, however, these cells reacted differently in contact with wild and vaccine measles virus strains. Furthermore, we observed the presence of a significant proportion of non-responder vaccinees, which could not be easily explained by the disappearance of MeV-specific memory CD4 cells over time. Our study may have implications on the monitoring of the complexity of the post-vaccine immune response. 


\section{Acknowledgments}

We thank our colleagues who participated in this study and Elżbieta Gaińska and Gideon Rosenberg for editorial assistance. This research was supported by the Polish Ministry of Science and Higher Education (grant NN 404 107938).

\section{Literature}

Czarkowski M.P., E. Cieleba, P. Dacka and B. Kondej. 2007. Infectious diseases and poisonings in Poland in 2006. NIZP-PZH, GIS, Warsaw.

Częścik A., M. Dunal-Szczepaniak, A. Trzcińska and J. Siennicka. 2012. Presence of IgG class antibodies anti measles virus in sera of subjects in different age. Med. Dośw. Mikrobiol. 64: 73-78.

Sadowska-Galera M. 2009. Initial results and evaluation of IgG antibody levels for rubella, mumps, measles and chickenpox viruses in young adults born in 1989. Przegl. Epidemiol. 63: 365-369.

Czarkowski M.P., B. Kondej, E. Cieląbek and E. Staszewska. 2010. Vaccination in Poland in 2010. NIZP-PZH, GIS, Warsaw.

Chen R.T., L.E. Markowitz, P. Albrecht, J.A. Stewart, L.M. Mofenson, S.R. 1990. Preblud and W.A. Orenstein. Measles antibody: reevaluation of protective titers. J. Infect. Dis. 162: 1036-1042.

Janaszek W., W. Gut and N.J. Gay. 2000. The epidemiology of measles in Poland: prevalence of measles virus antibodies in the population. Epidemiol. Infect. 125: 385-392.

WHO. 1993. Immunological basis for immunization series. Module 7: Measles. World Health Organization, Geneva.

Nanan R., A. Rauch, E. Kämpgen, S. Niewiesk and H.W. Kreth. 2000. A novel sensitive approach for frequency analysis of measles virus-specific memory T-lymphocytes in healthy adults with a childhood history of natural measles. J. Gen. Virol. 81: 1313-1319.

Ovsyannikova I.G., N. Dhiman, R.M. Jacobson, R.A. Vierkant and G.A. Poland. 2003. Frequency of measles virus-specific CD4+ and CD8+ T cells in subjects seronegative or highly seropositive for measles vaccine. Clin. Diagn. Lab. Immunol. 10: 411-416.

Naniche D., M. Garenne, C. Rae, M. Manchester, R. Buchta, S.K. Brodine and M.B. Oldstone. 2004. Decrease in measles virusspecific CD4 T cell memory in vaccinated subjects. J. Infect. Dis. 190: 1387-1395.

Howe R.C., N. Dhiman, I.G. Ovsyannikova and G.A. Poland. 2005. Induction of CD4 $\mathrm{T}$ cell proliferation and in vitro Th1-like cytokine responses to measles virus. Clin. Exp. Immunol. 140: 333-342.

Haralambieva I.H., I.G. Ovsyannikova, N. Dhiman, R.A. Vierkant, R.M. Jacobson and G.A. Poland. 2010. Differential cellular immune responses to wild-type and attenuated edmonston tag measles virus strains are primarily defined by the viral phosphoprotein gene. J. Med. Virol. 82: 1966-1967.

Haralambieva I.H., I.G. Ovsyannikova, M. O'Byrne, V.S. Pankratz, R.M. Jacobson and G.A. Poland. 2011. A large observational study to concurrently assess persistence of measles specific B-cell and T-cell immunity in individuals following two doses of MMR vaccine. Vaccine 29: 4485-4491.

Jacobson R.M., I.G. Ovsyannikova, R.A. Vierkant, V.S. Pankratz and G.A. Poland. 2012. Independence of measles-specific humoral and cellular immune responses to vaccination. Hum. Immunol. 73: 474-479.

Czerkinsky C.C., L.A. Nilsson, H. Nygren, O. Ouchterlony and A. Tarkowski. 1983. A solid-phase enzyme-linked immunospot (ELISPOT) assay for enumeration of specific antibody-secreting cells. J. Immunol. Methods 65: 109-121.

Altman J.D., P.A. Moss, P.J. Goulder, D.H. Barouch, M.G. McHeyzer-Williams, J.I. Bell JI, A.J. McMichael and M.M. Davis. 1996. Phenotypic analysis of antigen-specific T lymphocytes. Science 274: 94-96.

Waldrop S.L., C.J. Pitcher, D.M. Peterson, V.C. Maino and L.J. Picker. 1997. Determination of antigen-specific memory/effector CD4+ T cell frequencies by flow cytometry: evidence for a novel, antigen-specific homeostatic mechanism in HIV-associated immunodeficiency. J. Clin. Invest. 99: 1739-1750.

Christenson B. and M. Böttiger. 1994. Measles antibody: comparison of long-term vaccination titres, early vaccination titres and naturally acquired immunity to and booster effects on the measles virus. Vaccine 12: 129-133.

Mossong J., D.J. Nokes, W.J. Edmunds, M.J. Cox, S. Ratnam and C.P. Muller. 1999. Modeling the impact of subclinical measles transmission in vaccinated populations with waning immunity. Am. J. Epidemiol. 150: 1238-1249.

Dhiman N., I.G. Ovsyannikova, J.E. Ryan, R.M. Jacobson, R.A. Vierkant, V.S. Pankratz, S.J. Jacobsen and G.A. Poland. 2005. Correlations among measles virus-specific antibody, lymphoproliferation and Th1/Th2 cytokine responses following measlesmumps-rubella-II (MMR-II) vaccination. Clin. Exp. Immunol. 142: 498-504.

Homann D., L. Teyton and M.B. Oldstone. 2001. Differential regulation of antiviral T-cell immunity results in stable CD8+ but declining CD4+ T-cell memory. Nat. Med. 7: 913-919.

Halwani R., M. Doroudchi, B. Yassine-Diab, L. Janbazian, Y. Shi, E.A. Said, E.K. Haddad and R.P. Sékaly. 2006. Generation and maintenance of human memory cells during viral infection. Springer Semin. Immunopathol. 28: 197-208. 
